\title{
Hıyarlarda salisilik asit uygulaması ile depolama süresinin uzatılması ve kalite kayıplarının azaltılması*
}

\author{
Ebrar ALTIKARDEŞ ${ }^{1}$, Mehmet Ali KOYUNCU ${ }^{1}$, Derya ERBAŞ ${ }^{1}$
}

1Isparta Uygulamalı Bilimler Üniversitesi, Tarım Bilimleri ve Teknolojileri Fakültesi, Bahçe Bitkileri Bölümü, ISPARTA

$*^{*} 1^{\text {th }}$ International Frutic Symposium (Optimizing Water Use in the Supply Chain of Fresh Produce) isimli sempozyumda poster olarak sunulmuş ve özet metin olarak basılmıștır.

Alınış tarihi: 13 Temmuz 2018, Kabul tarihi: 2 Ağustos 2018

Sorumlu yazar: Mehmet Ali KOYUNCU, e-posta:koyuncu.ma@gmail.com

\section{Öz}

Çalışmada, hıyarların (Cucumis sativus cv. 'Alaiye') depolama ve meyve kalitesi üzerine farklı dozlarda salisilik asit (SA) ve modifiye atmosfer paketlemenin (MAP) etkileri araştırılmıştır. Derimi yapılan hiyarlar vakit kaybetmeden laboratuvara getirilmiştir. Zedelenmiş olan meyveler seçildikten sonra farklı konsantrasyonlarda [0 (kontrol) 0.5, 1 and $2 \mathrm{mM}$ ] SA içeren solüsyonlara $10 \mathrm{dk}$ süre ile daldırılmıştır. Daldırma işlemlerinden sonra $30 \mathrm{dk}$ süre ile oda koșullarında kurutulmuștur. Kuruyan hıyarlar MAP'lara yerleştirilmiş ve 20 gün $8^{\circ} \mathrm{C}$ ve

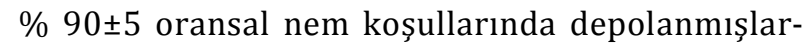
dır. Raf ömrü çalışmaları içinde soğukta muhafazadan sonra 2 gün $20^{\circ} \mathrm{C}$ ve $\% 60 \pm 5$ oransal nem koşullarında bekletilmiştir. Depolama başlangıcında ve 5'er gün aralıklarla ağırlık kaybı, meyve eti sertliği, meyve kabuk ve et rengi, solunum hızı ve MAP içi gaz bileşimi ölçümleri ile üşüme zararı ve duyusal değerlendirmeler yapılmıştır. Sonuç olarak, SA dozları kontrole göre incelenen kalite parametreleri açısından genellikle daha olumlu sonuçlar vermiştir. Fakat $1 \mathrm{mM}$ SA dozu ağırlık kaybının ve solunum hızının azaltılmasında ve sertliğin korunmasında en etkili uygulama olmuştur.

Anahtar kelimeler: Cucumis sativus, modifiye atmosfer paketleme, kalite, raf ömrü, 'Alaiye'
Prolonging storage life and delaying the quality losses of cucumber by salicylic acid

\begin{abstract}
In this research, the effects of modified atmosphere packaging (MAP) and salicylic acid (SA) treatment on the storage life and fruit quality of cucumber $\mathrm{cV}$. 'Alaiye' were investigated. Cucumbers were harvested at commercial harvest maturity stage and transported to laboratory immediately. Cucumbers were dipped in an aqueous solution containing different concentrations of SA [0 (control) 0.5, 1 and $2 \mathrm{Mm}$ ] for 10 minutes. After treatments, fruits were held at room conditions for drying during 30 minutes. Dried cucumbers were placed in modified atmosphere packages and stored for 20 days at $8^{\circ} \mathrm{C}$ and $90 \pm 5 \%$ relative humidity (RH). After cold storage, cucumbers were stored for 2 days at $20^{\circ} \mathrm{C}$ and $60 \pm 5 \% \mathrm{RH}$ for evaluation of shelf life. Weight loss, fruit flesh firmness, fruit flesh and skin color, respiration rate, chilling injury evaluation and sensory analyses were performed at the beginning and 5-day interval during cold storage. As a result, generally, all doses of SA gave better results than control groups in terms of some quality parameters. But $1 \mathrm{mM}$ dose of SA was the most effective treatment for decreasing weight loss, respiration rate, and maintaining fruit firmness.
\end{abstract}

Key words: Cucumis sativus, modified atmosphere packaging, quality, shelf life, 'Alaiye' 


\section{Giriş}

Sebzeler, içerdiği birçok vitamin ve besin maddeleri sayesinde insan sağlığı ve beslenmesi açısından oldukça önemlidir. Ancak sebzeler su içeriğinin yüksek olması ve derimden sonra da solunumlarının hızlı olmasından dolayı çabuk bozulabilmektedirler. Derim sonrası kayıpların da bu sebeplerden dolayı sebzelerde meyvelere göre daha yüksek olduğu bilinmektedir (Özcan ve Yazıcıoğlu, 2011). Genel olarak bu kayıpları (su kaybı, renk değişimi, fizyolojik ve patojen kaynaklı bozulmalar vb.) ve solunumlarını yavaşlatmak için ürünlerin derimden sonra vakit kaybetmeden soğuk zincire sokulması gerekmektedir (Doğan ve Erkan, 2014). Özellikle depolama süreleri sınırlı ve ihracat şansı yüksek olan hıyar, domates, biber gibi sebzelerin soğukta muhafaza koşullarının belirlenmesi ve derimden sonra hemen soğuk zincire dahil edilmesi önem arz etmektedir. MAP uygulamaları, uzun yıllardır meyve ve sebzelerin muhafaza süresini uzatmak ve muhafaza süresince kalite kayıplarını azaltmak amacı ile yaygın olarak kullanılmaktadır (Batu ve Demirdöven, 2010). MAP'la ilgili çalıșmalarda bu uygulamanın, meyve rengini ve parlaklığını koruduğu, meyve sertliğini koruyarak yumuşamayı geciktirdiği, ağırlık kaybını azalttığı, çürüklük gelişimini yavaşlattığı ve yaşlanmayı yavaşlatarak muhafaza ve raf ömrünü uzattığı bildirilmiștir (Singh et al., 2012; Laribi et al., 2012; Şen, 2013; Wani et al., 2014). Hıyarların depolanmasındaki en büyük problem, düşük sıcaklıklarda, kabuk üzerinde ete batmış lekecikler şeklinde belirtiler oluşturan, üşüme zararıdır (Ekinci ve Çelik, 1997; Akbudak ve Özer, 2003). Genellikle hiyarlar 7$10^{\circ} \mathrm{C}^{\prime}$ de $\% 90$-95 oransal nemde 10 gün kadar depolandıkları zaman üşüme zararı belirtilerinin ortaya çıktığını bildirilmiştir (Salunkhe and Desai, 1984; Akbudak ve Özer, 2003). Doğal ve güvenli bir bileşik olan salisilik asit (SA), aromatik bir halkaya sahip bitki fenoliklerinin bir grubudur (Özeker, 2005). Bitkilerde SA'nın hastalıklara dayanıklılık, fotosentez ve tohum çimlenmesi gibi birçok önemli olaya etki ettiği bilinmektedir (Ergun ve Kösetürkmen, 2008). Derim sonrası dönemde de etilen üretim miktarını ve solunum oranını azaltarak olgunlaşmayı geciktirdiği bildirilmiştir (Mo et al., 2008). Bunun yanı sıra derim sonrası SA uygulamalarının birçok üründe yumuşamaya sebep olan enzimlerin aktivitesini azaltarak yumuşamayı geciktirdiği, meyve rengini koruduğu ve üşüme zararını azalttığı kaydedilmiștir (Wang et al., 2006; Sayyari et al., 2009; Khademi et al., 2012; Awad, 2013; Razavi et al., 2014). Bu alanda yapılan çalışmalar incelendiğinde 'Alaiye' hıyar çeşidinde ya da diğer hıyar çeşitlerinde SA uygulamalarının hıyarların depolanmasında en önemli problem olan üşüme zararı üzerine etkilerini inceleyen bir araştırmaya rastlanmamıştır. Bu amaçla bu çalışmada 'Alaiye' hıyar çeşidinin depolama ve meyve kalitesi üzerine farklı dozlarda SA uygulamasının ve MAP'ın etkileri araştırılmıştır.

\section{Materyal ve Yöntem}

\section{Materyal ve uygulamalar}

Çalışmada meyve materyali olarak Antalya-Alanya mevkiinde yaygın olarak yetiştirilen ve tüketici tarafından yoğun olarak talep gören 'Alaiye' hıyar ( $\mathrm{Cu}$ cumis sativus) çeşidi kullanılmıştır. Meyveler Alanya'da bulunan bir üretici bahçesinden (6 Ağustos 2016) temin edilmiştir. Bu çeşidin meyveleri orta büyüklükte, parlak koyu yeşil renkte ve pürüzsüzdür. Sabahın erken saatlerinde derimi yapılan hıyarlar, Isparta Uygulamalı Bilimler Üniversitesi Tarım Bilimleri ve Teknolojileri Fakültesi Bahçe Bitkileri Bölümü Derim Sonrası Fizyolojisi Laboratuvarına soğutmalı araçla getirilmiş ve zedelenmiş olanlar seçildikten sonra SA (Sigma-Aldrich $\geq 99.0 \%$ ) uygulamaları için 4 gruba ayrılmıştır. İlk üç grup, 0.5 , 1 ve $2 \mathrm{mM}$ dozlarında SA $+\% 0.01^{\prime}$ lik Tween 20 içeren $\left(+4^{\circ} \mathrm{C}\right)$ solüsyonlara, son grup hiyarlar ise saf su $\left(+4^{\circ} \mathrm{C}\right)+\% 0.01^{\prime}$ lik Tween 20 (kontrol) solüsyona 10 $\mathrm{dk}$ süre ile daldırılmıștır. Daldırma işleminden sonra hıyarlar oda koşullarında $30 \mathrm{dk}$ kurutma kağıtlarının üzerinde bekletilmiştir. Kuruyan meyveler modifiye atmosfer poşetlerine (5 kg'lık, düşük yoğunluklu, polietilen bazlı ve hıyarlar için özel olarak üretilmiş) yerleştirilerek $8^{\circ} \mathrm{C}$ ve $\% 90 \pm 5$ oransal nem koşullarında 20 gün süre ile depolanmıştır. Depolama başlangıcında ve 5 gün aralıklarla çıkarılan hıyar örneklerinde yöntem bölümünde belirtilen analizler yapılmıştır. Raf ömrü çalışmaları için her analiz döneminde soğukta muhafazadan çıartılan hıyarlar $20^{\circ} \mathrm{C}$ 'de $\% 60 \pm 5$ oransal nem koşullarında 2 gün bekletilmiş ve aynı analizler tekrarlanmıştır.

\section{Yöntem}

Ağırlık kaybı, bu amaçla ayrılan poşetlenmiş örneklerin her dönem tartılıp başlangıç ağırlığına kıyaslanması yoluyla belirlenmiştir. Tartımı yapılan örnekler bir sonraki dönem tartılmak üzere tekrar soğuk odaya yerleştirilmiştir. Depolama boyunca her dönem çıkarılan poşetler $0.01 \mathrm{~g}$ hassasiyetteki terazi ile ölçülmüş ve \% olarak hesaplamıştır. Meyve eti sertliği ölçümleri deneme başlangıcında ve her analiz döneminde depolardan çlkarılan hıyarların ekvatoral 
çevresi boyunca iki ayrı yerden tekstür cihazı (Lloyd Marka LF Plus) ile yapılmıștır. Her tekerrürde 8 adet meyve kullanılmıştır. 1 KN'luk loadcell ile 100 $\mathrm{mm} / \mathrm{dk}$ değişmez hızda $8 \mathrm{~mm}$ çapındaki silindirik uç hıyarlarda, meyve kabuğunu ( $1 \mathrm{~cm}^{2}$ 'lik alan) uzaklaştırılarak $20 \mathrm{~mm}$ batırılmış ve elde edilen maksimum kuvvet Newton (N) cinsinden meyve eti sertliği olarak değerlendirilmiştir. Depolama süresince hıyarların kabuğunda ve etinde meydana gelen renk değişimleri, depolardan çıkartılan hıyar örneklerinde CR 300 model Minolta marka renk cihazı kullanılarak ölçülmüș ve sonuçlar CIE L*a*b* cinsinden verilmiştir. Renk ölçümleri meyvenin uzunlamasına 3 ayrı noktasından 2 taraflı olarak ölçülmüştür. Solunum hızı ölçümleri için depolama boyunca belirtilen aralıklarla depodan çıkarılan hıyarlar 3 L hacmindeki kavanozlara yaklaşık 500 g meyve olacak şekilde tartılıp $20{ }^{\circ} \mathrm{C}^{\prime}$ de 2 saat bekletilmiştir. Daha sonra kavanozlardan gaz sızdırmaz enjektör yardımıyla gaz örneği alınıp, gaz kromatografisi (Agilent GC$6890 \mathrm{~N}$ ) cihazına enjekte edilmiştir. Ölçümler S/SL inletin split modunda gaz örnekleme valfi ile $1 \mathrm{~mL}$ 'lik gaz örneğinde fused silica kapiler kolon (GCGASPRO, 30m, x 0,32 mm I.D.) kullanılarak solunum ölçümü için ısı iletkenlik dedektörü (TCD) bulunan GC ve bağlandığı bir bilgisayara yüklenen Chemstation A.09.03 [1417] paket programı kullanılarak belirlenmiştir. Sonuçlar ml $\mathrm{CO}_{2} \mathrm{~kg}^{-1} \mathrm{~h}^{-1}$ cinsinden hesaplanmiştır.

MAP içi gaz bileşimleri, gaz analizörü (Systec Instrument Gaspace) ile her analiz döneminde depodan çıkarılan poşetlerde yapılmıştır. Cihazın iğneli ucu poşet içerisine batırılarak, poşetlerdeki $\mathrm{CO}_{2}$ ve $\mathrm{O}_{2}$ seviyeleri \% olarak belirlenmiştir. Hıyarların duyusal değerlendirilmesinde tat için 1-5 skalası (1- çok kötü, 2- kötü, 3- orta, 4- iyi, 5- çok iyi), dış görünüş için 1-9 skalası (1/3- pazarlanamaz, 5- pazarlanabilir, 7- iyi, 9- çok iyi) ve üşüme zararı için 0-4 skalası (0-yok, 1-az, 2-orta, 3-orta şiddetli, 4-şiddetli) (Singh et al., 2009) kullanılmıştır. Değerlendirmeler flüoresan ışık altında ve kokusuz bir ortamda 5 kişilik eğitilmiş panelist grubu tarafından yapılmıştır.

Deneme tesadüf parselleri deneme desenine göre 3 tekerrürlü (her tekerrürde yaklaşık 4-4.5 kg hıyar) olarak kurulmuş ve elde edilen sonuçlar JMP v.7.0. istatistik paket programında varyans analizine tabi tutulmuştur. Ortalamalara ilișkin farklılıkların belirlenmesinde Tukey testi kullanılmıştır $(\mathrm{p}<0.05)$.

\section{Sonuçlar ve Tartışma}

\section{Ağırlık kaybı}

Ağırlık kaybı, pazarlanacak ürünün ağırlığındaki azalmayı ifade ettiği için meyve ve sebzelerin depolanmasında önemli bir parametredir. Depolama boyunca hıyarların ağırlık kaybında meydana gelen değişimler Çizelge 1'de sunulmuştur. 'Alaiye' hıyar çeşidinde soğukta muhafaza boyunca SA $(0.5 \mathrm{mM}$ $\% 2.12,1 \mathrm{mM} \% 2.34$ ve $2 \mathrm{mM} \% 2.27)$ uygulamalarının kontrol grubuna (\%2.75) oranla ağırlık kaybını azalttığı saptanmıştır. Uygulamaların kontrole göre bu olumlu etkisi raf ömrü koşullarında da görülmüştür. SA uygulamalarının ağırlık kaybı üzerine olan bu olumlu etkilerini, Babalar et al. (2007), SA'nın olgunlaşma ve metabolizmayı yavaşlatması ve bozulmaları engellemesi ile ilişkilendirilebileceğini ve Zheng and Zhang (2004) ise SA'nın ağırlık kaybını stomaları kapatarak yavaşlatabileceğini ifade etmişlerdir. Mevcut çalışma sonuçlarına benzer şekilde Shafiee et al. (2010), SA uygulamasının çileklerde bozulmaları ve ağırlık kaybını azalttığını bildirmişlerdir.

Çizelge 1. Depolama boyunca hıyarlarda meydana gelen ağırlık kayıpları (\%)

\begin{tabular}{|c|c|c|c|c|c|}
\hline Uygulamalar & 5. gün & 10. gün & 15. gün & 20. gün & Ortalamalar \\
\hline Kontrol & $0.82 \mathrm{c}$ & $1.66 \mathrm{c}$ & $3.62 \mathrm{~b}$ & $4.90 \mathrm{a}$ & 2.75 \\
\hline $0.5 \mathrm{mM}$ & $0.67 \mathrm{c}$ & $1.55 \mathrm{c}$ & $3.31 \mathrm{~b}$ & $3.83 \mathrm{ab}$ & 2.34 \\
\hline $1 \mathrm{mM}$ & $0.69 \mathrm{c}$ & $1.42 \mathrm{c}$ & $3.22 \mathrm{~b}$ & $3.16 \mathrm{~b}$ & 2.12 \\
\hline $2 \mathrm{mM}$ & $0.75 \mathrm{c}$ & $1.35 \mathrm{c}$ & $3.58 \mathrm{~b}$ & $3.38 \mathrm{~b}$ & 2.27 \\
\hline \multirow[t]{2}{*}{ Ortalamalar } & 0.74 & 1.49 & 3.43 & 3.82 & \\
\hline & $5+2$.gün & 10+2. gün & 15+2. gün & 20+2. gün & \\
\hline Kontrol & 1.28 & 2.94 & 5.24 & 7.07 & $4.13 \mathrm{~A}^{*}$ \\
\hline $0.5 \mathrm{mM}$ & 1.35 & 2.78 & 4.4 & 6.06 & $3.65 \mathrm{BC}$ \\
\hline $1 \mathrm{mM}$ & 1.32 & 2.19 & 4.11 & 5.84 & $3.36 \mathrm{C}$ \\
\hline $2 \mathrm{mM}$ & 1.25 & 2.58 & 4.75 & 6.79 & $3.84 \mathrm{AB}$ \\
\hline Ortalamalar & $1.30 \mathrm{~d}^{*}$ & $2.62 \mathrm{c}$ & $4.62 \mathrm{~b}$ & $6.44 \mathrm{a}$ & \\
\hline
\end{tabular}

* Farklı harflerle gösterilen ortalamalar arasındaki fark istatistik olarak önemlidir $(\mathrm{p}<0.05)$. 


\section{Meyve eti sertliği}

Sertlik, hıyarların derim sonrası kalitesi ve pazar değeri açısından önemli faktörlerden biridir. Meyve eti sertliği uygulamalara bakılmaksızın depolama boyunca azalmış fakat SA uygulanan hıyarların yumuşaması hem soğukta depolama hem de oda koşullarında kontrollere oranla daha yavaş olmuştur (Çizelge 2). Raf ömrü sürecinde hıyarlardaki yumuşama soğukta muhafazaya oranla daha hızlı olmuştur. Bu durumu yüksek sıcaklıkların ve düşük oransal nemin ürünlerde su kaybını arttırmasına ve metabolik olayları hızlandırmasına, dolayısıyla meyve yumuşamasını da hızlandırmasına dayandırabiliriz. Ayrıca MAP uygulamalarının birçok bahçe ürününde protopektin parçalanmasını geciktirerek meyve sertliğini koruduğu da bildirilmiştir (Şen, 2013). Soğukta muhafaza başlangıcında $43.40 \mathrm{~N}$ olan sertlik değeri 20 günlük depolama sonunda kontrol grubunda $18.79 \mathrm{~N}, 2 \mathrm{mM}$ SA uygulamasında $20.52 \mathrm{~N}, 1 \mathrm{mM}$ 'da $23.87 \mathrm{~N}$ ve 0.5 mM SA uygulamasında da $24.25 \mathrm{~N}$ olarak ölçülmüştür. Genel ortalamalar incelendiğinde $1 \mathrm{mM} \mathrm{SA}$ uygulaması her iki depolama koşulunda da sertliğin korunması bakımından en iyi uygulama olmuştur. Tüm dozlar için SA uygulanmış hıyarlar depolama sonunda kontrol grubuna göre daha sert kalmıştır. Çalışmalarda SA uygulamalarının, meyve yumuşamasına sebep olan enzimlerin parçalamasını engelleyerek (Zhang et al., 2003) ve SA'nın kısmen de olsa membran bütünlüğünü koruyarak sertliği etkileyebileceği ifade edilmiştir (Sayyari et al., 2009).

\section{Meyve kabuk ve et rengi}

Hıyarlarda derim kriteri olarak kullanılan kabuk rengi, tazeliğinde göstergesi olan kalite parametrelerinden birisidir (Nilsson, 2005). Çalışmada, parlaklığı ifade eden $\mathrm{L}^{*}$ değeri depolama boyunca hem kabukta hem de meyve etinde dalgalanmalar göstermekle beraber, ortalama değerler incelendiğinde başlanglca oranla depolama sonunda bütün uygulamalarda genellikle artmıştır. L* değerindeki bu artışı kabukta ve meyvedeki renk tonlarının açılması ile açıklanabilir. 20+2 günlük raf ömrü süreci sonunda kontrol grubunda meyve kabuk rengi $0.5 \mathrm{mM}$ ve $1 \mathrm{mM} \mathrm{SA}$ uygulamasından daha yüksek değerler almıştır (Şekil 1). Bu durum, özellikle depolamanın $15+2$. gününden sonra kontrol grubunda, üşüme zararı belirtilerinin ve bozulmaların artması dolayısıyla yeşil rengin açılması ile ilişkilendirilebilir. Nitekim üşüme zararı ve dış görünüş puanları da bu durumu destekler niteliktedir (Şekil 4). Eksi değerlerinin yeşil rengi ifade ettiği a* değeri depolama boyunca meyve kabuğunda artarken, meyve etinde azalmıştır (Şekil 1, Şekil 2). Kabuktaki a* değeri artışını ürünlerdeki su kaybının fazla olmasına dolayısıyla rengin matlaşarak daha fazla koyulaşmasıyla ilișkilendirebiliriz. Meyve kabuğundaki renk değişimi Şen (2013)'in hıyarlarla yaptığı çalışmayla paralellik göstermektedir. Artı değerler aldığında sarı rengi ifade eden $b^{*}$ değeri ise meyve kabuğunda depolama boyunca artarken, meyve etinde azalmıştır. Meyve kabuğundaki b* değeri artışı ürünlerin yaşlanmasıyla birlikte klorofillerinin parçalanması ve yeşil rengin sarıya dönmesinden kaynaklanmaktadır. Bütün SA uygulamaları rengin korunması açısından kontrol grubuna göre her iki depolama koşulunda da daha iyi sonuçlar vermiştir. SA uygulamalarının ürünlerin solunumunu ve metabolizmasını yavaşlatarak yaşlanmayı geciktirdiği dolayısıyla yaşlanmaya bağlı renk gibi kalite parametrelerinin korunmasını sağladığı önceki çalışmalarda bildirilmiştir (Peng and Jian, 2006; Khademi et al., 2012; Awad, 2013).

Çizelge 2. Depolama boyunca hıyarlarda meydana gelen meyve eti sertliği değişimleri (N)

\begin{tabular}{ccccccc}
\hline Uygulamalar & 0. gün & 5. gün & 10. gün & 15. gün & 20. gün & Ortalamalar \\
\hline Kontrol & $43.40 \mathrm{a}$ & $39.99 \mathrm{ab}$ & $29.72 \mathrm{~d}$ & $23.88 \mathrm{efg}$ & $18.79 \mathrm{~g}$ & 31.16 \\
$0.5 \mathrm{mM}$ & $43.40 \mathrm{a}$ & $41.14 \mathrm{ab}$ & $30.46 \mathrm{~d}$ & $29.69 \mathrm{~d}$ & $24.25 \mathrm{ef}$ & 33.79 \\
$1 \mathrm{mM}$ & $43.40 \mathrm{a}$ & $40.94 \mathrm{ab}$ & $36.42 \mathrm{bc}$ & $29.71 \mathrm{~d}$ & $23.87 \mathrm{efg}$ & 34.87 \\
$2 \mathrm{mM}$ & $43.40 \mathrm{a}$ & $41.27 \mathrm{ab}$ & $32.06 \mathrm{~cd}$ & $26.98 \mathrm{de}$ & $20.52 \mathrm{fg}$ & 32.85 \\
\hline Ortalamalar & 43.4 & 40.84 & 32.17 & 27.57 & 21.86 & \\
\hline Kontrol & $0+2$. gün & $5+2$. gün & $10+2$. gün & $15+2$. gün & $20+2$. gün & 24.46 öd $^{*}$ \\
$0.5 \mathrm{mM}$ & 36.93 & 33.47 & 24.07 & 16.15 & 11.69 & 26.18 \\
$1 \mathrm{mM}$ & 38.18 & 34.56 & 25.92 & 18.27 & 13.98 & 26.60 \\
$2 \mathrm{mM}$ & 38.49 & 36.48 & 26.69 & 17.94 & 13.41 & 25.10 \\
\hline Ortalamalar & 36.41 & 35.89 & 24.92 & 16.84 & 11.42 & $12.62 \mathrm{~d}$ \\
\hline
\end{tabular}

* öd: önemli değil. Farklı harflerle gösterilen ortalamalar arasındaki fark istatistik olarak önemlidir $(\mathrm{p}<0.05)$. 

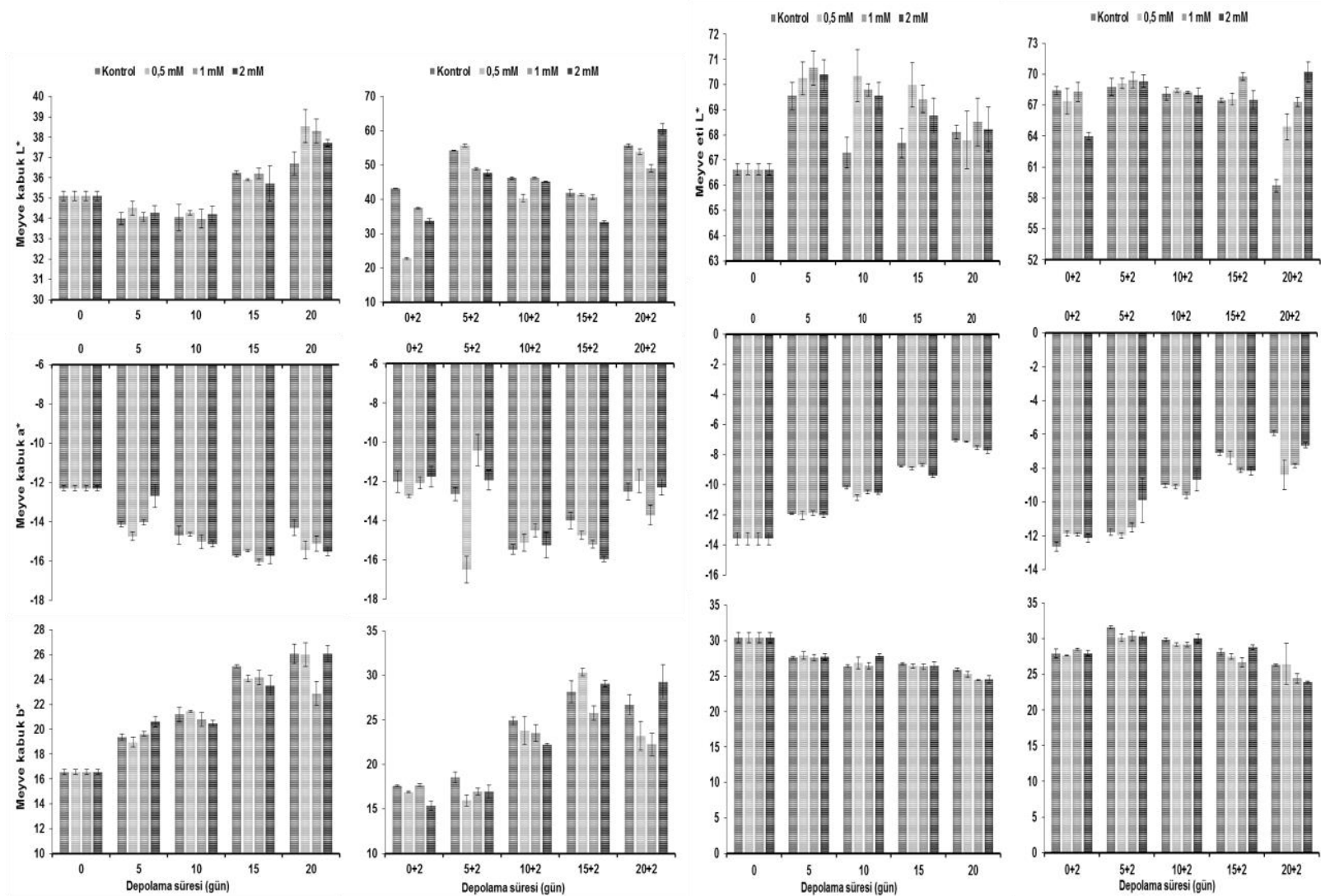

Şekil 1. Depolama boyunca hıyarlarda meydana gelen meyve kabuk rengi değișimleri (CIEL*a*b*) *Hata barları: Ortalama \pm standart hata $(n=3)$

\section{Solunum hızı ve modifiye atmosfer poșet içi gaz bileşimi}

Depolama boyunca meydana gelen solunum hızı ve modifiye atmosfer poşet içi gaz bileşimi değerleri Şekil 3'te sunulmuştur. Depolama boyunca hıyarların solunum hızları başlangıç değerlerine göre düzenli artmıştır. 20 günlük muhafaza periyodu sonunda SA uygulamasının bütün dozları kontrole göre solunum hızını önemli ölçüde düşürmüştür. Başlangıçta 0.280 $\mathrm{ml} \mathrm{CO}_{2} \mathrm{~kg}^{-1} \mathrm{~h}^{-1}$ olarak ölçülen solunum hızları 20. gün sonunda kontrol uygulamasinda $1.900 \mathrm{ml} \mathrm{CO}_{2} \mathrm{~kg}^{-1} \mathrm{~h}^{-}$ 1, $1 \mathrm{mM}$ dozunda $1.492 \mathrm{ml} \mathrm{CO}_{2} \mathrm{~kg}^{-1} \mathrm{~h}^{-1}, 2 \mathrm{mM}$ dozunda $1.334 \mathrm{ml} \mathrm{CO}_{2} \mathrm{~kg}^{-1} \mathrm{~h}^{-1}$ ve $0.5 \mathrm{mM}$ dozunda da 1.196 $\mathrm{ml} \mathrm{CO}_{2} \mathrm{~kg}^{-1} \mathrm{~h}^{-1}$ olarak ölçülmüştür. Ortalamalara bakıldığında ise $1 \mathrm{mM}$ SA dozu solunumu en iyi baskılayan uygulama olmuştur. Luo et al. (2011) ve Erbaş ve ark. (2015) farklı bahçe ürünleriyle yaptıkları çalışmalarında derim öncesi veya derim sonrası SA uygulamalarının solunumu baskıladığını belirtmişlerdir. Benzer sonuçlar raf ömrü sürecinde de elde edilmiştir (veriler gösterilmemiştir). Depolama boyunca MAP içindeki $\mathrm{O}_{2}(\%)$ seviyesi giderek azalırken, $\mathrm{CO}_{2}$ oranı da artmıștır. Muhafaza sonunda en

Şekil 2. Depolama boyunca hıyarlarda meydana gelen meyve et rengi değişimleri (CIEL*a*b*) *Hata barları: Ortalama \pm standart hata $(n=3)$

düşük $\mathrm{O}_{2}$ ve en yüksek $\mathrm{CO}_{2}$ oranı kontrol grubundan (\%10.1-\%8.0, sırasıyla) elde edilirken, en yüksek $\mathrm{O}_{2}$ ve en düşük $\mathrm{CO}_{2}$ değeri $1 \mathrm{mM}$ dozundan (\%11.9\%7.1, sırasıyla) elde edilmiştir. Sonuçlar çalışmadaki solunum hızı değerlerini de destekler niteliktedir.

\section{Duyusal değerlendirmeler ve üşüme zararı}

Meyve ve sebzelerde depolama süresinin, duyusal kaliteyi etkilediği bilinmektedir (Echeverria et al., 2008). Araştırmada depolama süresinin uzamasına paralel olarak tat ve dış görünüş değerleri azalırken üşüme zararı da artmıștır (Şekil 4). SA uygulamaları her iki depolama koşulunda da kontrole kıyasla tat bakımından olumlu sonuçlar vermiştir. Meyveler soğukta depolamanın 15. gününde tat bakımından orta düzeyde değerlendirilirken, raf ömrü koşullarında 10+2. günde bu seviyelerde puanlanmıștır (3.17 puan-2.50 puan arasında). Üşüme zararı belirtilerinin depolamanın 10. gününden itibaren kısmen ortaya çıtığı göz önüne alındığında, üşüme zararı ile tat arasında bir ilişki olabileceği düşünülmektedir. Üşüme zararı arttıkça tat puanları düşmüştür (Şekil 4). 

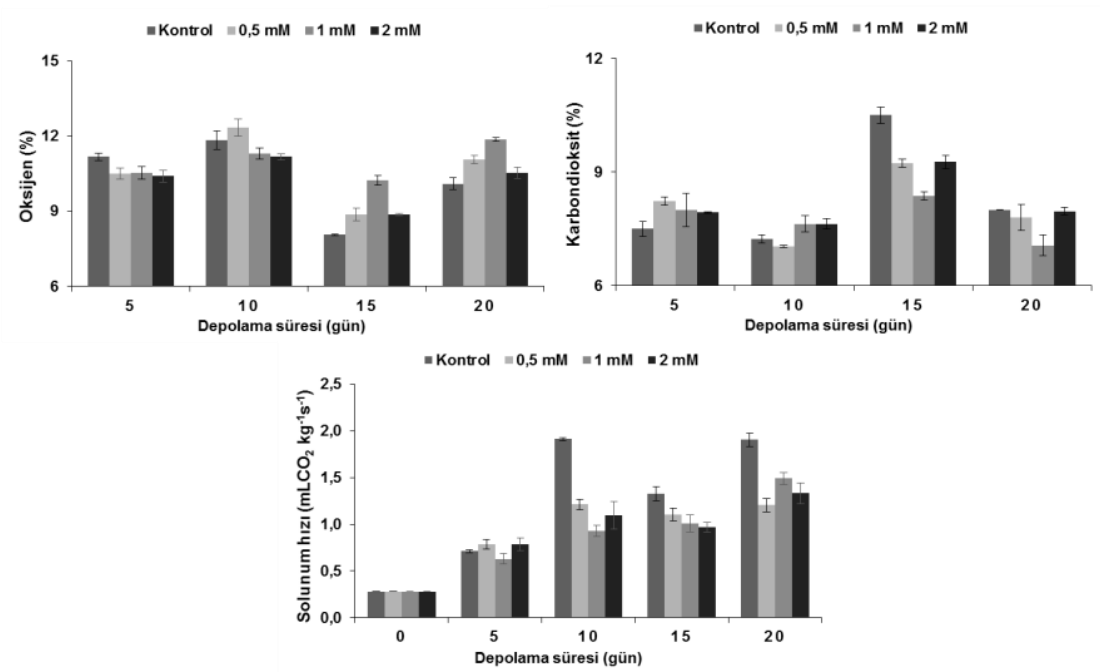

Şekil 3. Depolama boyunca hıyarlarda meydana gelen solunum hızı değişimleri ile MAP içi gaz bileşimi değişimleri; *Hata barları: Ortalama \pm standart hata $(n=3)$
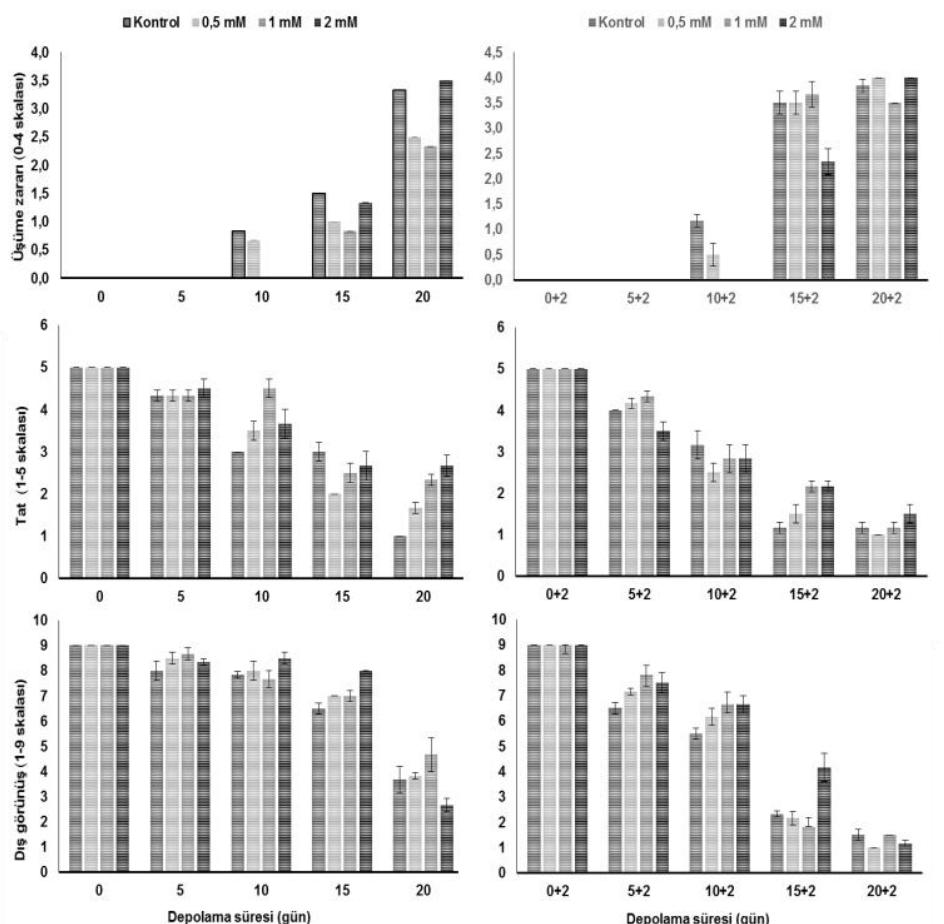

Şekil 4. Depolama boyunca hıyarların dış görünüş, tat ve üşüme zararı puanlarındaki değişimler; *Hata barları: Ortalama \pm standart hata (n=3): Dış görünüş 1 - 9 skalası; 1- 3: pazarlanamaz, 5: pazarlanabilir, 7: iyi, 9: çok iyi. Tat değerleri 1 - 5 skalası; 1: çok kötü, 2: kötü, 3: orta, 4: iyi, 5: çok iyi. Üşüme zararı değerleri 0 - 4 skalası: 0: yok, 1: çok az, 2: az, 3: orta, 4: şiddetli.

Muhafaza süresi uzadıkça dış görünüş puanları da sürekli olarak azalmıştır. 15 günlük depolama boyunca bütün uygulamalar dış görünüş bakımından pazarlanabilir puanları alsalar da, muhafaza sonunda dış görünüş bakımından en etkili sonuçlar $1 \mathrm{mM} \mathrm{SA}$ dozundan elde edilmiştir. Raf ömrü çalışmalarında da soğukta muhafazayla paralel sonuçlar elde edil- miştir. Taze meyve ve sebzelerdeki ağırlık ya da su kaybı \% 3 ile \% 6'lara ulaştığında, yüzeydeki büzüşmelerin ve kurumaların daha belirgin hale geldiğ $i$ bilinmektedir (Hardenburg et al., 1986). Bu doğrultuda dış görünüş bakımından elde edilen sonuçlar ağırlık kaybıyla uyumlu görünmektedir (Çizelge 1). Çalışmada, üşüme zararı belirtilerinin ilk olarak çok 
sayıda küçük çukurlar halinde ortaya çıktığı, daha sonra büyük noktalar oluştuğu ve en sonunda da bu noktaların sulanmış-yapışkan bir hal aldığı görülmüştür. Bütün bu belirtiler kontrol grubu meyvelerinde daha hızlı ortaya çıkmış ve $8^{\circ} \mathrm{C}$ 'den $20^{\circ} \mathrm{C}^{\prime}$ ye aktarıldıktan sonra daha da belirgin hale gelmiştir. Üşüme zararı belirtileri her iki depolama koşulunda da 10. günde görülmeye başlanmış ve tüm SA dozları kontrol grubuna göre üşüme zararını azaltmada etkili olmuştur. Depolama sonunda üşüme zararı bakımından en etkili uygulamanın $1 \mathrm{mM}$ SA dozu olduğu tespit edilmiştir. SA uygulamalarının üşüme zararını azalttığına dair benzer bulgular Wang et al. (2006), Cai et al. (2006), Ding et al. (2007) ve Sayyari et al. (2009)'nın çalışmalarından da elde edilmiştir.

Çizelge 3. İncelenen kalite parametrelerinin dönem, uygulama ve dönem $\times$ uygulama interaksiyonlarının önemlilik dereceleri

\begin{tabular}{|c|c|c|c|c|c|c|c|}
\hline \multirow{2}{*}{\multicolumn{2}{|c|}{ Parametreler }} & \multicolumn{3}{|c|}{ Soğukta muhafaza } & \multicolumn{3}{|c|}{ Raf ömrü } \\
\hline & & Dönem (D) & Uygulama (U) & $\mathrm{D} \times \mathrm{U}$ & $\mathrm{D}$ & $\mathrm{U}$ & $\mathrm{D} \times \mathrm{U}$ \\
\hline \multicolumn{2}{|c|}{ Ağırlık kaybı } & $* *$ & $*$ & $* *$ & $* *$ & $* *$ & öd \\
\hline \multicolumn{2}{|c|}{ Sertlik } & $* *$ & $* *$ & $* *$ & $* *$ & öd & öd \\
\hline \multicolumn{2}{|c|}{ Üșüme zararı } & $* *$ & $*$ & öd & $* *$ & $* *$ & $* *$ \\
\hline \multicolumn{2}{|c|}{ Diș görünüș } & $* *$ & öd & $*$ & $* *$ & $* *$ & $* *$ \\
\hline \multicolumn{2}{|c|}{ Tat } & $* *$ & $*$ & $* *$ & $* *$ & $* *$ & $* *$ \\
\hline \multicolumn{2}{|c|}{ Solunum hizı } & $*$ & $* *$ & $* *$ & $* *$ & $*$ & öd \\
\hline \multirow{3}{*}{$\begin{array}{l}\text { Meyve kabuk } \\
\text { rengi }\end{array}$} & $\mathrm{L}^{*}$ & $* *$ & $*$ & öd & $* *$ & öd & $* *$ \\
\hline & $a^{*}$ & $* *$ & $*$ & öd & $* *$ & öd & öd \\
\hline & $b^{*}$ & $* *$ & $* *$ & öd & $* *$ & $*$ & öd \\
\hline \multirow{3}{*}{ Meyve et rengi } & $\mathrm{L}^{*}$ & $* *$ & öd & $*$ & $*$ & öd & $*$ \\
\hline & $a^{*}$ & $* *$ & öd & öd & $* *$ & $* *$ & öd \\
\hline & $b^{*}$ & $* *$ & $*$ & öd & $* *$ & $*$ & öd \\
\hline \multirow{2}{*}{$\begin{array}{c}\text { Poşet içi gaz } \\
\text { bileşimi }\end{array}$} & $\mathrm{O}_{2}$ & $* *$ & öd & öd & - & - & - \\
\hline & $\mathrm{CO}_{2}$ & $* *$ & $*$ & öd & - & - & - \\
\hline
\end{tabular}

*; \% 5 önemli, **; \% 1 önemli, öd: önemli değil $(\mathrm{p}<0.05)$.

Çalışmada incelenen tüm kalite parametreleri bakımindan, SA uygulamaları genel olarak kontrol grubuna göre hem soğukta muhafaza hem de oda koşullarında daha iyi sonuçlar vermiştir. Duyusal değerlendirmeler ve üșüme zararı puanları dikkate alındığ zaman, kontrol uygulamasında hıyarlar 10+2 gün ve $1 \mathrm{mM}$ SA uygulamasında ise soğukta 15 gün pazarlanabilir kalitede kalabilmişlerdir. 0.5 ve $2 \mathrm{mM}$ uygulamaları ise ortalama değerler incelendiğinde depolama süresi bakımından kontrol ile $1 \mathrm{mM}$ SA uygulaması arasında yer almıştır. 15+2 günlük sürenin sonunda ise tüm uygulamalarda meyveler pazarlanabilir niteliğini yitirmiștir.

\section{Kaynaklar}

Akbudak, B., Özer, M.H., 2003. Farklı sıcaklıklarda muhafaza edilen turşuluk hıyarlarda meydana gelen fiziksel ve kimyasal değişimler. Uludağ Üniversitesi Ziraat Fakültesi Dergisi, 17 (1): 33-46.

Awad, R.M., 2013. Effect of post-harvest salicylic acid treatments on fruit quality of peach cv. Flordaprince during cold storage. Australian Journal of Basic and Applied Science, 7 (7): 920-927.
Babalar, M., Asghari, M., Talaei, A., Khosroshahi, A., 2007. Effect of pre- and postharvest salicylic acid treatment on ethylene production, fungal decay and overall quality of Selva strawberry fruit. Food Chemistry, 105: 449-453.

Batu, A., Demirdöven, A., 2010. Modifiye atmosferde paketleme ve soğukta depolamanın elmanın duyusal kalitesi üzerine etkileri. Yüzüncü Yıl Üniversitesi Tarım Bilimleri Dergisi, 20 (2): 58-67.

Cai, C., Li, X., Chen, K.S., 2006. Acetylsalicylic acid alleviates chilling injury of postharvest loquat (Eribotrya japanica Lindl.) fruit. European Food Research and Technology, 223: 533-539.

Ding, Z.S., Tian, S.P., Zheng, X.L., Zhou, Z.W., Xu, Y., 2007. Responses of reactive oxygen metabolism and quality in mango fruit to exogenous oxalic acid or salicylic acid under chilling temperature stress. Physiologia Plantarum, 130 (1): 112-121.

Doğan, A., Erkan, M., 2014. Bahçe ürünlerinin muhafazasında yeni bir teknoloji: Palistore ortamında depolama. Meyve Bilimi, 1: 1-6.

Echeverria, G., Graell, J., Lara, I., Lopez M.L., 2008. Physicochemical measurements in Mondial Gala apples stored at different atmospheres: Influence on consumer acceptability. Postharvest Biology and Technology, 50 (2-3): 135-144. 
Ekinci, N., Çelik, S., 1997. Bazı hıyar çeşitlerinde lentisel yoğunluğunun muhafaza süresi ve kalite özelliklerinin değişimi üzerine etkisi. Bahçe Ürünlerinin Muhafaza ve Pazarlama Sempozyumu (21-24 Ekim 1997, Yalova) Bildirileri, 207-212.

Erbaș, D., Onursal, C.E., Koyuncu, M.A., 2015. Derim sonrası salisilik asit uygulamasının Aprikoz kayısı çeşidinin soğukta depolanması üzerine etkileri. Meyve Bilimi, 2 (2): 50-57.

Ergun, M., Kösetürkmen, N., 2008. Jasmonik ve salisilik asit uygulamalarının rendelenmiş taze havuç kalitesi üzerine etkileri. Harran Üniversitesi Ziraat Fakültesi Dergisi, 12 (1): 49-55.

Hardenburg R.E., Watada A.E., Wang C.Y., 1986. The Commercial Storage of Fruits, Vegetables, and Florist and Nursery Stocks, Agriculture Handbook No. 66. Washington (D.C.): US Department of Agriculture. Agricultural Research Service, USA, 130 pp.

Khademi, O., Zamani, Z., Mostofi, Y., Kalantari, S., Ahmadi, A., 2012. Extending storability of persimmon fruit cv. Karaj by postharvest application of salicylic acid. Journal of Agricultural Science and Technology, 14 (5): 1067-1074.

Laribi, A.I., Palou, L., Intrigliolo, D.S., Nortes, P.A., Rojas Argudo, C., Taberner, V., Bartual, J., Perez-Gago, M. B., 2012. Effect of sustained and regulated deficit irrigation on fruit quality of pomegranate cv. 'Mollar de Elche' at harvest and during cold storage. Agricultural Water Management, 125: 61-70.

Luo, Z., Chen, C., Xie, J., 2011. Effect of salicylic acid treatment on alleviating postharvest chilling injury of 'Qingnai' plum fruit. Postharvest Biology and Technology, 62 (2): 115-120.

Mo, Y., Gong, D., Liang, G., Han, R., Xie, J., Li, W., 2008. Enhanced preservation effects of sugar apple fruits by salicylic acid treatment during post-harvest storage. Journal of the Science of Food and Agriculture. 88 (15): 2693-2699.

Nilsson, T., 2005. Effects of ethylene and 1-MCP on ripening and senescence of European seedless cucumbers. Postharvest Biology and Technology, 36 (2): 113-125.

Özcan, M., Yazıcıoğlu, E., 2011. Samsun ili bahçe bitkileri tarımının hasat ve hasat sonrası sorunları ve çözüm önerileri. Samsun Sempozyumu (13-16 Ekim 2011, Samsun) Bildirileri, 165-168.

Özeker, E., 2005. Salisilik asit ve bitkiler üzerindeki etkileri. Ege Üniversitesi Ziraat Fakültesi Dergisi, 42 (1): 213-223.
Peng, L., Jiang Y., 2006. Exogenous salicylic acid inhibits browning of fresh-cut chinese water chestnut. Food Chemistry, 94: 535-540.

Razavi, F., Hajilou, J., Dehgan, G., Band Hassani, R. N., Turchi, M., 2014. Enhancement of postharvest quality of peach fruit by salicylic acid treatment. International Journal of Biosciences, 4(1): 177-184.

Salunkhe, D.K., Desai, B.B., 1984. Postharvest Biotechnology of Vegetables-Volume II. CRC-Press, Boca Raton, Florida, 216 pp.

Sayyari, M., Babalar, M., Kalantari, S., Serrano, M., Valero, D., 2009. Effect of salicylic acid treatment on reducing chilling injury in stored pomegranates. Postharvest Biology and Technology, 53 (3): 152-154.

Shafiee, M., Taghavi, T. S., Babalar, M., 2010. Addition of salicylic acid to nutrient solution combined with postharvest treatments (hot water, salicylic acid, and calcium dipping) improved postharvest fruit quality of strawberry. Scientia Horticulturae, 124 (1): 40-45.

Singh, S. P., Singh, Z., Swinny, E. E., 2009. Postharvest nitric oxide fumigation delays fruit ripening and alleviates chilling injury during cold storage of japanese plums (Prunus salicina Lindell). Postharvest Biology and Tech, 53 (3): 101-108.

Singh, P., Wani, A. A., Goyal, G. K., 2012. Shelf-life extension of fresh ready-to-bake pizza by the application of modified atmosphere packaging. Food and Bioprocess Technology, 5 (3):1028-1037.

Şen, F., 2013. Farklı ambalajlarda muhafaza edilen hıyar (Cucumis sativus l.) meyvelerinin kalite değişimleri. Süleyman Demirel Üniversitesi Ziraat Fakültesi Dergisi, 4 (1): 60-70.

Wang, I., S. Chen, W. Kong, S., Li, Archbuld, D., 2006. Salicylic acid pretreatment alleviates chilling injury and affect the antioxidant system and heat shock proteins of peach during cold storage. Postharvest Biology and Technology, 41 (3): 244-251.

Wani, A. A., Singh, P., Guld, K., Wani, M. H., Langowski, H. C., 2014. Sweet cherry (Prunus avium): Critical factors affecting the composition and shelf life. Food Packaging Shelf Life, 1 (1):86-99.

Zhang, Y., Chen, K., Zhang, S., Feguson, I., 2003. The role of salicylic acid in postharvest ripening of kiwifruit. Postharvest Biology and Technology, 28: 67-74.

Zheng, Y., Zhang, Q., 2004. Effects of polyamines and salicylic acid on postharvest storage of 'Ponkan' mandarin. Acta Horticiculturae, 632: 317-320. 